\title{
Avaliação de diferentes formulações de compostos elastoméricos SBR/NR visando minimizar a pré-vulcanização
}

\author{
Evaluation of different formulations \\ of SBR/NR elastomeric compounds \\ in order to minimize pre-vulcanization
}

\author{
Sérgio Gomes de Souza ${ }^{1}$, Giulia Herbst ${ }^{1}$, Marcia Luciane Lange Silveira ${ }^{1}$ \\ Ana Paula Kurek ${ }^{2}$, Noeli Sellin ${ }^{2}$
}

\author{
${ }^{1}$ Departamento de Engenharia Química, UNIVILLE, Campus Universitário, Zona Industrial Norte, 98219 710, Joinville, \\ Santa Catarina, Brasil. \\ ${ }^{2}$ Mestrado em Engenharia de Processos, UNIVILLE, Campus Universitário, Zona Industrial, 98219 710, Joinville, Santa \\ Catarina, Brasil. \\ e-mail: anapkurek@gmail.com
}

\begin{abstract}
RESUMO
Este trabalho teve como objetivo desenvolver e avaliar novas formulações para o sistema de vulcanização em compostos elastoméricos a base de borracha estireno-butadieno (SBR) e borracha natural (NR), visando reduzir a formação de compostos pré-vulcanizados pelo aumento no tempo de armazenamento antes do processamento. Foram desenvolvidas formulações alternativas em relação a uma formulação padrão empregada por uma empresa do setor, variando-se os componentes do sistema de vulcanização (ativadores, agentes e aceleradores). As formulações foram avaliadas por ensaios de reologia, ensaios de resistência à tração e alongamento na ruptura, dureza, deformação permanente por compressão (DPC), envelhecimento acelerado em estufa e densidade absoluta. Foram observadas variações significativas nas propriedades dos compostos com as modificações realizadas nos sistemas de vulcanização (S1, S2, S3, P1 e P2), quando comparados com o sistema de vulcanização padrão (S0), principalmente, quando foram utilizados peróxidos orgânicos, como agente de vulcanização. De todas as formulações avaliadas, a que utilizou doador de enxofre e uma maior razão acelerador/enxofre, em relação ao sistema de vulcanização padrão apresentou todas as propriedades de acordo com a especificação técnica exigida para o composto padrão (S0) e redução no tempo de armazenamento e minimização da pré-vulcanização.
\end{abstract}

Palavras-chave: doadores de enxofre, peróxidos orgânicos, razão acelerador/enxofre, tempo de scorch

\section{ABSTRACT}

This work aimed to develop and evaluate new formulations for the rubber vulcanization system based on styrene-butadiene rubber (SBR) and natural rubber (NR), aiming at reducing the formation of pre-vulcanized compounds by increasing storage time before processing. Alternative formulations have been developed in relation to a standard formulation employed by a company of the sector, varying the components of the vulcanization system (activators, agents and accelerators). The formulations were evaluated by rheology tests, tensile strength and elongation at break, hardness, permanent compression deformation (DPC), accelerated aging in greenhouse and absolute density. There were significant variations in the properties of the compounds with the modifications made in the vulcanization systems ( 1 1, S2, S3, P1 and P2), when compared with the standard vulcanization system (S0), mainly when organic peroxides were used as agent of vulcanization. Of all the formulations evaluated, the one that used sulfur donor and a higher accelerator / sulfur ratio, compared to the standard vulcanization system showed all properties according to the technical specification required for the standard compound (S0) with reduction in the time of storage and minimization of pre-vulcanization.

Keywords: Sulfur donors, organic peroxides, accelerator/sulfur ratio, scorch time.

\section{INTRODUÇÃO}


O desenvolvimento de novos materiais elastoméricos tem ocorrido a partir de misturas envolvendo duas ou mais matrizes elastoméricas já conhecidas e/ou por incorporação de aditivos a estas composições. O tipo de ligação formada depende do sistema de vulcanização utilizado, do tempo e da temperatura de vulcanização [1]. A escolha dos aditivos a serem incorporados é realizada de acordo com as propriedades desejadas para o material elastomérico e sua aplicação, podendo fornecer maior velocidade de vulcanização, maior segurança de processo e melhor desempenho mecânico [2]. O processo de vulcanização também interfere na formação de ligações cruzadas e, consequentemente, nas propriedades mecânicas do material como por exemplo, vulcanização em prensa e autoclave, mostraram que para determinada formulação, nas mesmas condições de temperatura, o método de vulcanização por autoclave se mostrou mais eficiente em relação às propriedades mecânicas [3]. A sequência de adição, ordem em que os aditivos são introduzidos em composições contendo mistura de elastômeros exercem grande influência nas propriedades físico-mecânicas $[1,4]$.

A vulcanização é uma das etapas que necessitam de maior controle das variáveis do processo de produção de artefatos elastoméricos. Nesta etapa, a adição de enxofre ou agentes de cura ao elastômero, sob altas temperaturas e pressão e por determinado período, promovem a formação de ligações cruzadas (reticulação), normalmente, nos pontos de insaturação dos átomos de carbono da cadeia macromolecular do material. A formação de ligações cruzadas no material elastomérico ocasionadas por óxidos metálicos, peróxidos e aminas também é chamada de vulcanização ou cura. Estas alterações na estrutura química do material mudam seu estado, transformando-o de plástico e altamente deformável para elástico e, consequentemente, as propriedades mecânicas (módulo, dureza, tensão de ruptura, deformação permanente à compressão e alongamento) do composto elastomérico vulcanizado também são alteradas [3,4]. O tempo e a temperatura de vulcanização também influenciam fortemente nas propriedades finais do composto elastomérico e as melhores condições operacionais são definidas em função das propriedades desejadas para a aplicação do mesmo.

O índice de peças ou artefatos de borracha refugados é relativamente alto no processo de produção, muitas vezes em função de ocorrer a pré-vulcanização do material durante seu armazenamento antes da etapa de cura (vulcanização), dificultando sua moldagem. Este período de armazenamento é denominado tempo de Scorch, que é o tempo necessário para aquecer o composto a uma determinada temperatura, fazendo com que a viscosidade diminua permitindo menor plasticidade e maior fluidez, de maneira que o composto preencha perfeitamente toda a cavidade do molde, ou seja, retarde a formação de ligações cruzadas antes da peça estar moldada. Além disso, há também desperdícios gerados pela produção de rebarbas oriundas das etapas de moldagem e acabamento. Estes materiais refugados são geralmente descartados em aterros, tornando-se um passivo ambiental, principalmente devido à sua resistência a degradação [5, 6, 7].

Pesquisas para diminuição de refugos gerados durante a produção, principalmente na etapa de vulcanização, são poucas, porém são de extrema relevância [8, 9, 10,11, 12]. Na literatura são encontrados estudos sobre o desenvolvimento de novas tecnologias para a reutilização de artefatos de borracha pósconsumo, principalmente de pneus [12].

Na etapa de vulcanização, muitas variações são possíveis, entre estas, o tipo da borracha usada. A borracha natural (NR) é conhecida por apresentar excelente desempenho mecânico, tendo sua estrutura química formada por cadeias de hidrocarbonetos insaturados com alta regularidade, o que permite a esta borracha cristalizar por resfriamento ou quando submetida ao estiramento [1,13]. Outra opção é o copolímero de butadieno-estireno (SBR), um material apolar que apresenta bom desempenho mecânico, alta resistência ao envelhecimento, elevada rigidez e menor custo quando comparada à NR [14].

Outras variações ocorrem devido à adição de diferentes tipos, quantidade e combinações de componentes, como os aceleradores de vulcanização (peróxido orgânico e doadores de enxofre) e agentes de vulcanização (ditiocarbamatos e tiazóis). Com o emprego destes dois grupos de matérias-primas, calor e pressão, as cadeias elastoméricas se unirão tornando este material mais resistente a óleos, solventes, produtos químicos, com maior resistência à deformação e elasticidade [15].

Os doadores de enxofre têm influência nos tipos de ligações formadas, pois quando o teor de enxofre é reduzido, ocorre menor quantidade de ligações polissulfídicas e com isso menor resistência ao calor, ocasionando resultados mais elevados de deformação permanente por compressão em comparação com as ligações dissulfídicas e monossufídicas. Idealmente, todo o enxofre adicionado deve gerar ligações cruzadas, e a quantidade adicionada deve ser a mínima necessária para se alcançar as propriedades desejadas $[2,16]$.

Os aceleradores podem ser classificados em relação à velocidade de vulcanização, podendo ser lentos, médio, rápidos e muito rápidos. Normalmente, no processo de produção de borrachas são utilizados mais de um tipo de acelerador em um composto elastomérico, proporcionando diferentes propriedades físicas e químicas, e alteração no tempo de Scorch ou pré-vulcanização. O tipo de acelerador usado deve permanecer 
inativo neste período, proporcionando maior segurança de processamento, devido ao fato de evitar a formação significativa de ligações cruzadas, diminuindo a ocorrência de compostos pré-vulcanizados que geram refugos no processo produtivo de artefatos de borracha $[4,17]$.

Visando melhoria no tempo de armazenamento antes do processamento do composto elastomérico e minimizar a geração de resíduos, este trabalho teve como objetivo desenvolver e avaliar diferentes formulações para um sistema de vulcanização de compostos a base de borracha estireno-butadieno (SBR) e borracha natural (NR). As amostras obtidas a partir das novas formulações foram caracterizadas por reologia, ensaios de resistência à tração e alongamento, dureza, deformação permanente por compressão (DPC), envelhecimento acelerado em estufa e densidade absoluta, e suas propriedades foram comparadas com amostras obtidas de uma formulação padrão de uma empresa do setor de borrachas.

\section{MATERIAIS E MÉTODOS}

$\mathrm{Na}$ Tabela 1 estão apresentadas as matérias-primas, os fabricantes e as quantidades (em phr - partes por 100 de borracha) que foram utilizadas para o preparo do composto base. As borrachas SBR e NR foram misturadas em um misturador do tipo Banbury (Marca Bonfanti / Modelo BMI-40P) e, em seguida, adicionadas às matérias-primas na formulação conforme indicado na Tabela 1. A Indústria de Artefatos de Borracha Wolf Ltda, cedeu os materiais e a linha de produção para o estudo.

Tabela 1: Matérias-primas, fabricantes e quantidades (em phr - partes por 100 de borracha) para preparo do composto base.

\begin{tabular}{c|c|c}
\hline \multicolumn{2}{c}{ Componentes do composto } & phr \\
\hline Descrição da matéria-prima & Fabricante & 70 \\
\hline Copolímero de estireno butadieno SBR 1502 (SBR) & Lanxess & 30 \\
\hline Borracha natural GEB1 (NR) & Usina Santa Helena & 5 \\
\hline Óxido de zinco 99 \% & Votorantim & 2,5 \\
\hline Polietileno glicol PEG 4000 & Oxiteno & 40 \\
\hline Carbonato de cálcio extra leve & Quinvale & 31,5 \\
\hline Sílica precipitada em pó & Rhodia & 6,7 \\
\hline Dióxido de titânio rutilo & Lanxess & 1,0 \\
\hline Fenol estirenado & Proquitec & 21 \\
\hline Óxido de cálcio (CaO) & Proquitec & 64,5 \\
\hline Óleo naftênico & Ninas &
\end{tabular}

Os componentes para a formulação do composto base (Tabela 1) foram misturados por $300 \mathrm{~s}$. num misturador fechado tipo Banbury (Marca Bonfanti / Modelo BMI-40P), aquecidos até $125{ }^{\circ} \mathrm{C}$ e resfriados com auxílio de ventiladores e divididos em seis partes iguais e, em seguida, foram adicionados os componentes do sistema de vulcanização (Tabela 2), obtendo as amostras de diferentes formulações a serem avaliadas. 
Tabela 2: Componentes dos sistemas de vulcanização, valores expressos em phr - partes por 100 de borracha.

\begin{tabular}{|c|c|c|c|c|c|c|c|}
\hline \multicolumn{8}{|c|}{ Componentes do sistema de vulcanização } \\
\hline Matéria-prima & Fabricante & S0 & S1 & S2 & S3 & P1 & $\mathbf{P 2}$ \\
\hline Ácido esteárico granulado & Sim Estearina & 1,9 & 1,9 & 1,9 & 1,9 & - & - \\
\hline Enxofre superventilado & Intercuf & 2,3 & 1,6 & 1,0 & 0,5 & - & - \\
\hline Peróxido orgânico de dicumila 99\% & Akzo Nobel & - & - & - & - & 2,0 & 1,5 \\
\hline Dissulfeto de tetrametil tiuram (TMTD) & Lanxess & 0,8 & 1,2 & 1,5 & 2,0 & - & - \\
\hline Dissulfeto de mercaptobenzotiazol (MBTS) & Lanxess & 0,5 & - & - & - & - & - \\
\hline $\begin{array}{l}\text { N-Ciclohexil-2-benzotiazolsulfenamida } \\
\text { (CBS) }\end{array}$ & Lanxess & 0,8 & 1,5 & 1,7 & 2,0 & - & - \\
\hline Dietil-ditiocarbamato de zinco (ZDEC) & Lanxess & 0,4 & - & - & - & - & - \\
\hline 4,4-ditiomorfolina (DTDM) & Lanxess & - & 1,5 & 2,5 & 3,5 & - & - \\
\hline $\mathrm{N}$-(ciclohexiltio) ftalamida (PVI) & Lanxess & 0,4 & - & - & - & - & - \\
\hline
\end{tabular}

( - ) Matérias-primas que não foram utilizadas na formulação em avaliação. S0 - formulação padrão; S1, S2 e S3 - com enxofre; P1 e P2 - com peróxido orgânico.

Após a adição dos componentes dos sistemas de vulcanização (Tabela 2), as amostras foram avaliadas quanto ao tempo de Scorch em função do tempo de armazenamento, por meio de ensaios de reologia. Os ensaios foram realizados com tempo de 3 minutos e a $175^{\circ} \mathrm{C}$, em um reômetro de cavidade oscilante (Marca TI / Modelo MDR, marca TI), seguindo a norma ASTM D 5289 (ASTM, 2001) [18].

As amostras obtidas foram vulcanizadas e, após a obtenção dos compostos elastoméricos na forma de placas, foram efetuados os cortes dos corpos de prova tipo gravata utilizando faca e prensa pneumática, conforme ASTM D412 (ASTM, 2006) [19]. Estes corpos de prova foram utilizados para ensaios de resistência a tração e alongamento, ensaios de dureza Shore A e envelhecimento acelerado em estufa e densidade absoluta. Foram também realizados os testes de deformação permanente à compressão (DPC) e densidade absoluta, em corpos de prova obtidos especificamente para estes testes.

Os ensaios de tração e alongamento foram realizados em máquina de ensaios universal, (Marca Emic / Modelo DL 2000), de coluna dupla, com velocidade de ensaio de $500 \mathrm{~mm} / \mathrm{min}$., força máxima de $20 \mathrm{KN}$, limite de deformação de $800 \mathrm{~mm}$ e limite de força $450 \mathrm{~N}$. Cinco corpos de provas de cada formulação foram submetidos ao ensaio, conforme a Norma ABNT NBR 7462 (ABNT, 1992) [20].

O ensaio de envelhecimento acelerado em estufa foi realizado seguindo a norma ASTM D 573 (ASTM, 1999 reapr. 2015) [21]. Os corpos de provas foram colocados em estufa (Marca Nova Ética / Modelo 400 - 5ND) com ar circulante a $70( \pm 3)^{\circ} \mathrm{C}$ por $70( \pm 2)$ h. Após o término do ensaio, os corpos de prova foram retirados da estufa e deixados resfriar a $23( \pm 2)^{\circ} \mathrm{C}$, sob uma superfície plana. $\mathrm{O}$ ensaio de dureza Shore A foi realizado em cinco amostras, após o ensaio de envelhecimento acelerado em estufa. Utilizou-se durômetro de bancada (Marca Tecno / Modelo 9TEC-35539A), seguindo a norma ABNT 7318 (ABNT, 215) [22].

Os testes de deformação permanente à compressão (DPC) foram realizados de acordo com a norma ASTM D 395 (ASTM, 2001) [23]. Os corpos de prova foram vulcanizados em molde adequado para o ensaio, em triplicata. A temperatura de realização do teste foi de $70{ }^{\circ} \mathrm{C}$ e os corpos de prova foram submetidos à compressão por $22 \mathrm{~h}$.

A densidade absoluta foi determinada pelo método hidrostático e realizada conforme a norma ASTM D 297 (ASTM, 1993 reapr. 1998) [24]. Foram utilizados cinco corpos de prova tipo "batoque", com diametro de $13 \mathrm{~mm} \pm(0,2 \mathrm{~mm})$ e espessura de $6,0 \mathrm{~mm} \pm(0,2 \mathrm{~mm})$, e balança analítica (Marca Mettler).

Os resultados dos ensaios obtidos para cada um dos compostos preparados a partir das diferentes formulações propostas para o sistema de vulcanização foram comparados com a norma ASTM D2000 M4 AA 405 B33, especificada para o composto padrão (S0). 


\section{RESULTADOS E DISCUSSÕES}

\subsection{Ensaios de Reologia}

Na Figura 1 estão apresentados os resultados dos ensaios de reologia do composto elastomérico padrão e dos compostos obtidos com as diferentes formulações propostas para o sistema de vulcanização em função do tempo de armazenamento.

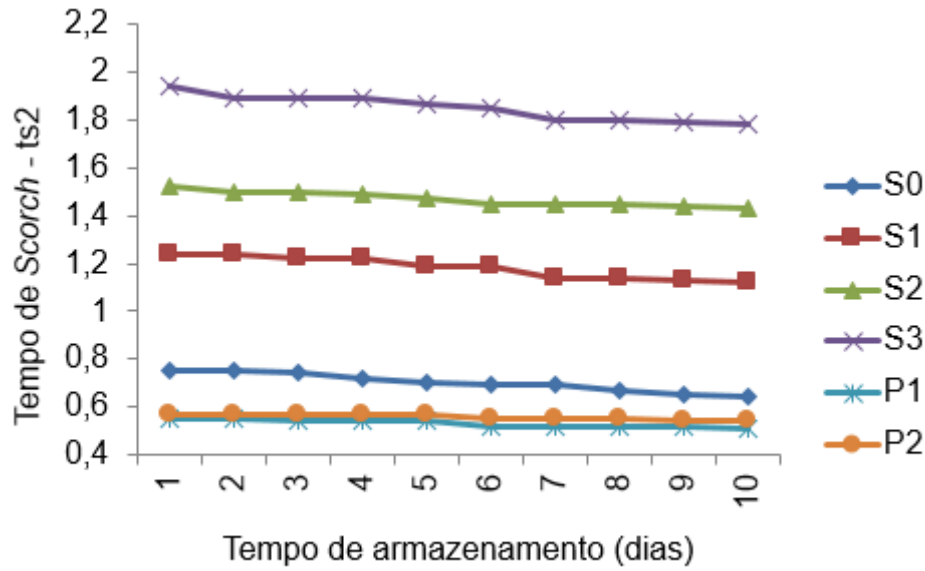

Figura 1: Resultados dos ensaios de reologia do composto padrão e dos obtidos com as diferentes formulações propostas para o sistema de vulcanização em função do tempo de armazenamento.

Os resultados encontrados nas amostras $\mathrm{S} 1, \mathrm{~S} 2, \mathrm{~S} 3$ foram relativamente melhores em relação ao tempo de Scorch (ts2) inicial ( $1^{\circ}$ dia útil) quando comparados com o composto padrão (S0). Nota-se que conforme a quantidade de enxofre foi diminuída nas formulações, substituindo parte do enxofre por doadores de enxofre, o tempo de Scorch (ts2) aumentou consideravelmente. Para os compostos P1 e P2, quando comparados com S0, observa-se que ocorreu diminuição no tempo de $\operatorname{Scorch}$ (ts2). Foi verificado alteração percentual de 7,27 $\%$ e $5,26 \%$ para P1 e P2, respectivamente, para o teste inicial realizado no $1^{\circ}$ dia útil quando comparado com o do $10^{\circ}$ dia útil. Uma das vantagens do sistema de vulcanização com peróxido é a maior duração dos compostos em armazenamento, sem ocorrer a pré-vulcanização [25].

Nos compostos contendo o sistema de vulcanização por enxofre S0, S1, S2 e S3, comparando o teste inicial realizado no $1^{\circ} \mathrm{com}$ o $10^{\circ}$ dia útil, verifica-se uma diminuição percentual no tempo de $\operatorname{Scorch}$ (ts2) em relação ao tempo de armazenamento de 14,69\% para o sistema de vulcanização padrão (S0), o qual para o S1 foi de $9,67 \%$, S2 de $5,92 \%$ e S3 de 7,73\%, resultados estes devido a substituição de parte do enxofre por por doadores de enxofre.

\subsection{Ensaio de Resistência à Tração e Alongamento}

Na Figura 2 são apresentados os resultados de (a) resistência à tração e (b) alongamento do composto padrão e dos obtidos com as diferentes formulações propostas para o sistema de vulcanização.

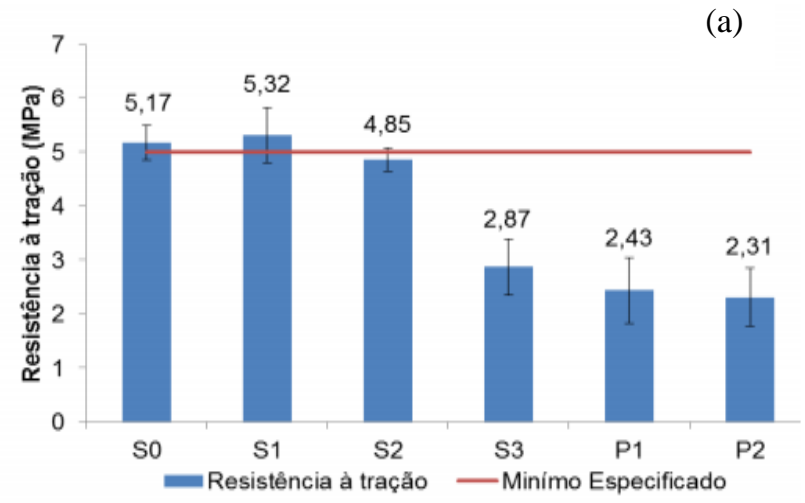


(b)

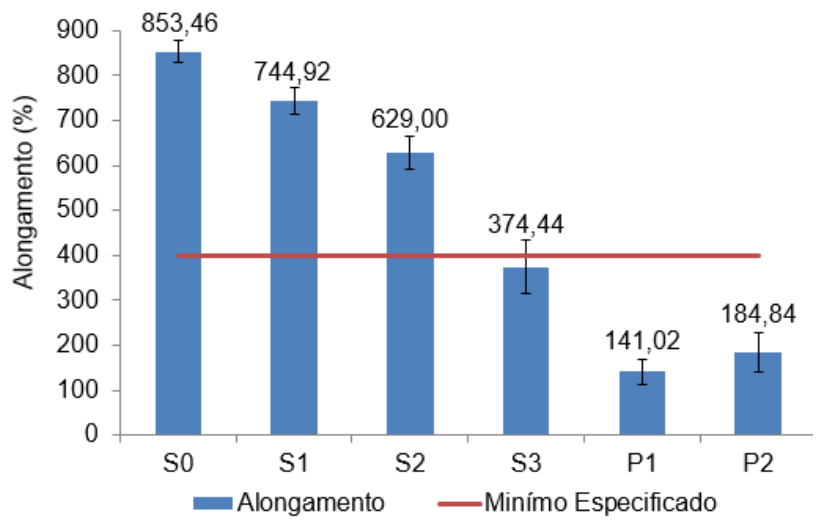

Figura 2: Ensaios de (a) resistência à tração e (b) alongamento do composto padrão e dos obtidos com as diferentes formulações propostas para o sistema de vulcanização.

De acordo com a especificação técnica, a resistência à tração mínima para o composto elastomérico deve ser $\geq 5 \mathrm{MPa}$ e o alongamento $\geq 400 \%$. Observando os resultados obtidos para as formulações testadas (Figura 2a), apenas a formulação S1 apresentou valores de resistência à tração de acordo com a especificação técnica. Os sistemas de vulcanização S2, S3, P1 e P2 apresentaram resultados de até $50 \%$ inferior ao especificado para esta propriedade. Em sistemas de vulcanização empregando maiores teores de enxofre ocorrem maiores formações de ligações polissufídicas que tem a habilidade de quebrarem-se causando maior flexibilidade molecular [3,4].

As formulações S0, S1, S2 apresentaram resultados de acordo com a especificação técnica para o alongamento (Figura 2b), com uma diminuição gradativa, proporcional a diminuição do enxofre, em relação ao composto SO. OLIVEIRA et al. [3] sugere que este comportamento pode estar relacionado com o aumento da razão acelerador/enxofre ocasionando um menor número de ligações do tipo polissufídicas que tornam a mobilidade das cadeias elastoméricas menores, e consequentemente resultam em menores valores no alongamento conforme mostra a Figura 2(b). Para os sistemas de vulcanização P1 e P2 com peróxidos orgânicos como agente de vulcanização, observou-se a diminuição do alongamento pois, este tipo de agente de vulcanização age como um radical livre fazendo com que as ligações das cadeias elastoméricas sejam formadas entre carbono-carbono (C-C), proporcionando menor mobilidade das cadeias quando comparadas com o sistema de vulcanização com enxofre [26].

\subsection{Ensaio de Dureza}

A Figura 3 apresenta os resultados da especificação técnica do composto em relação à dureza Shore A que é de $40 \pm 5$ Shore "A". Os resultados de dureza obtidos nos sistemas de vulcanização S0, S1, S2, S3 apresentaram valores condizentes com a especificação técnica. Segundo ARAVANIS [26] a utilização de um maior teor de enxofre apresenta maior dureza Shore A, o que não foi constatado neste ensaio, pois os compostos que continham menores teores de enxofre e apresentaram durezas Shore A maiores que o sistema de vulcanização S0, o qual era o composto com maior teor de enxofre na formulação. Já os sistemas de vulcanização que utiliza peróxidos orgânicos P1 e P2 não atenderam a especificação técnica, o que pode estar relacionado com o excesso de peróxido de dicumila $99 \%$, proporcionando assim um aumento na dureza Shore A [25]. 


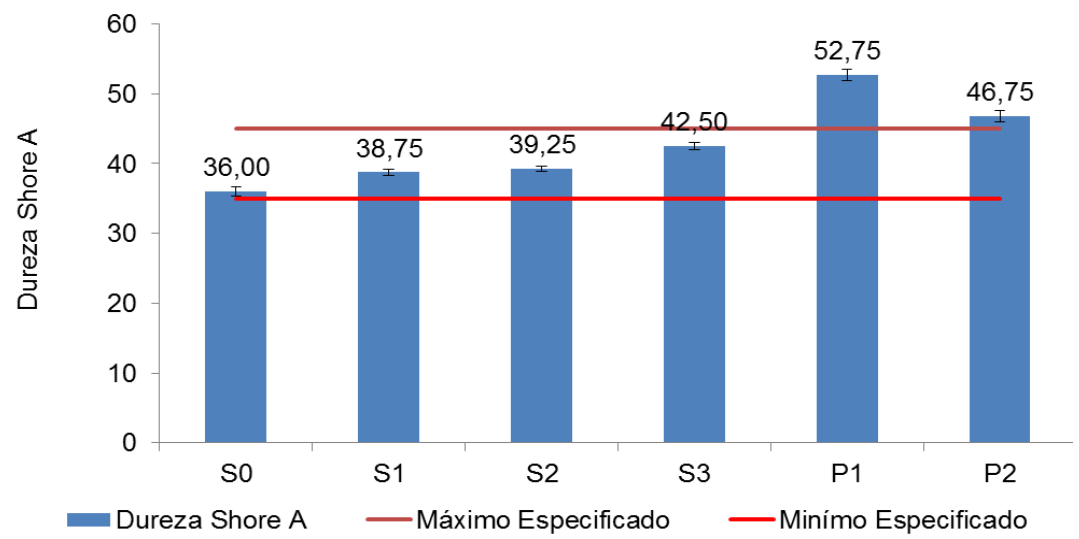

Figura 3: Ensaio de Dureza Shore A para o composto padrão e dos obtidos com as diferentes formulações propostas para o sistema de vulcanização.

\subsection{Ensaio de Deformação Permanente por Compressão (DPC)}

Os ensaios de deformação permanente à compressão (DPC) foram realizados com o objetivo de aferir a habilidade das composições de borracha em manter propriedades elásticas após ação de uma força compressiva. Durante esse ensaio as amostras foram expostas a uma temperatura de $70{ }^{\circ} \mathrm{C}$ ao longo de 22 horas, o que pode ocasionar uma leve degradação térmica, que acarretaria em perdas nas propriedades elásticas.

Na Figura 4, estão apresentados os resultados de deformação permanente por compressão do composto padrão e dos compostos obtidos a partir das diferentes formulações propostas.

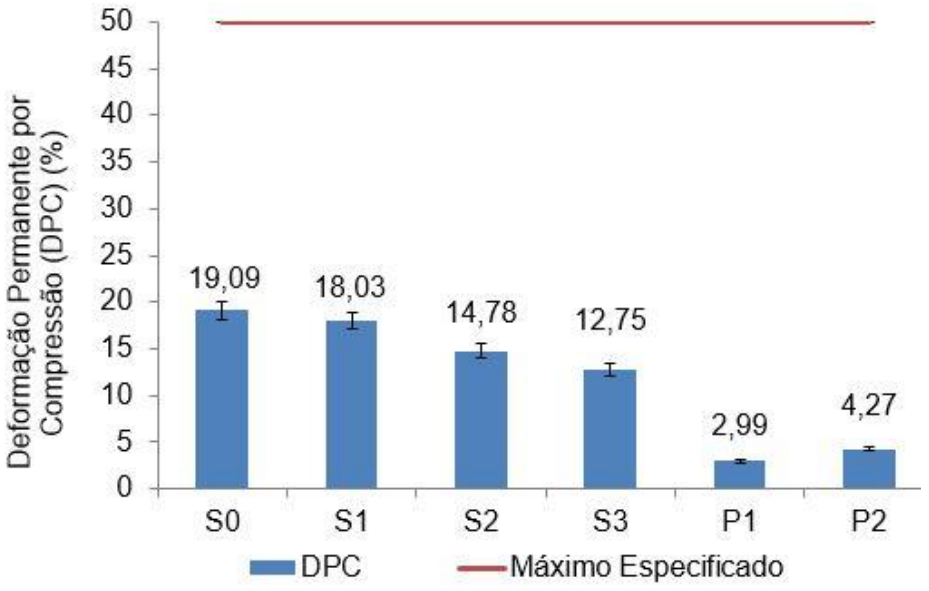

Figura 4: Deformação permanente por compressão (DPC) (\%) do composto padrão e dos obtidos com as diferentes formulações propostas para o sistema de vulcanização.

Para este ensaio, quanto maior o valor de DPC, menor tende a ser a capacidade do material elastomérico em manter suas propriedades elásticas. Conforme a Figura 4 observa-se que todos os sistemas de vulcanização avaliados apresentaram valores de DPC de acordo com os exigidos pela especificação técnica, que deve ser $\leq 50 \%$, conforme a norma ASTM D2000 M4AA 405 B33. Observou-se uma diminuição dos valores de DPC, com o aumento da razão acelerador/enxofre e o emprego de doadores de enxofre, para os sistemas de vulcanização S1, S2, S3, pois a quantidade de enxofre utilizado nestas formulações foi menor quando comparado com o sistema de vulcanização padrão (S0). Segundo GRISON et al. [25], ao diminuir o teor de enxofre e aumentar o teor de doadores de enxofre e a razão acelerador/enxofre ocorre uma menor quantidade de ligações do tipo polissufídicas, que sob aquecimento se desfazem, promovendo a degradação da peça ou redução das propriedades dinâmico-mecânicas. Conforme MILANI $e t$ al. [16] a quantidade de ligações polissufídicas dependem tanto da composição do composto de borracha 
(tipo e concentrações do sistema de vulcanização do enxofre) quanto das condições de reação, temperatura e tempo de vulcanização. Nos sistemas de vulcanização contendo o peróxido orgânico como agente de vulcanização (formulações P1 e P2) foram encontrados os menores valores de DPC. Conforme ARAVANIS [26], as formulações com peróxido orgânico, favorecem a formação de ligações carbono-carbono (C-C) durante a vulcanização e são termicamente mais estáveis.

\subsection{Envelhecimento acelerado em estufa}

A especificação técnica para o ensaio de dureza Shore A após envelhecimento acelerado em estufa estabelece uma alteração $\leq 10$ pontos. Conforme observado na Figura 5, os resultados indicam que as diferentes alterações nos sistemas de vulcanização não proporcionaram grandes variações neste ensaio, pois todos os sistemas de vulcanização atenderam a especificação técnica. Mas é importante salientar que os resultados de durezas Shore A dos compostos P1 e P2 se encontravam fora da especificacão técnica.

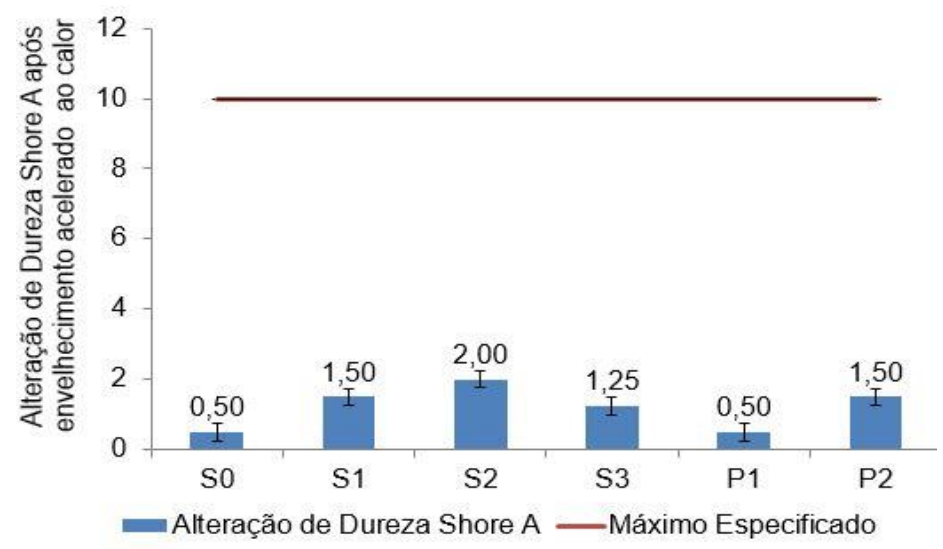

Figura 5: Ensaio de alteração de Dureza Shore A após envelhecimento acelerado em estufa do composto padrão e dos obtidos com as diferentes formulações propostas para o sistema de vulcanização.

Na Figura 6 está apresentado o efeito das alterações realizadas nos sistemas de vulcanização avaliados em relação ao ensaio de resistência à tração após envelhecimento acelerado em estufa, sendo a especificação técnica para este ensaio uma alteração máxima de $-25 \%$.

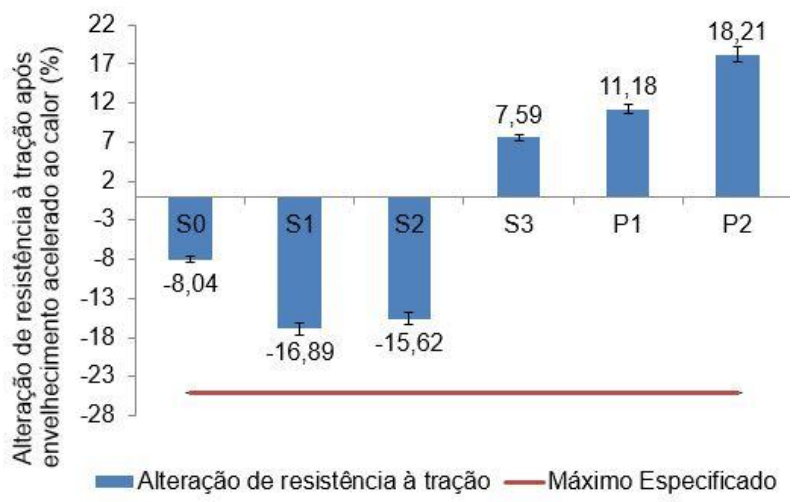

Figura 6: Ensaio de alteração de tração após envelhecimento acelerado em estufa (\%) do composto padrão e dos obtidos com as diferentes formulações propostas para o sistema de vulcanização.

Os resultados observados para as amostras S1, S2 apresentaram valores condizentes com a especificação técnica, mas divergem da literatura, pois quando utiliza-se doadores de enxofre e, quanto maior for à razão acelerador/enxofre, há uma tendência a formação de ligações do tipo monossulfídicas e dissulfídicas, que favorece a estabilidade térmica do elastômero Assim, deveria ter proporcionado melhores resultados no ensaio de envelhecimento acelerado em estufa em relação ao sistema de vulcanização S0 que 
contem maior teor de enxofre e tendência de formação de ligações do tipo polissulfídicas [3, 4]. As amostras S3, P1 e P2 apresentaram resultados positivos para este ensaio, não tendo valores condizentes com o especificado, pois somente são estabelecidos valores negativos.

A Figura 7 mostra os resultados dos ensaios de alongamento após envelhecimento em estufa, para este ensaio a especificação técnica é de $-25 \%$ máximo.

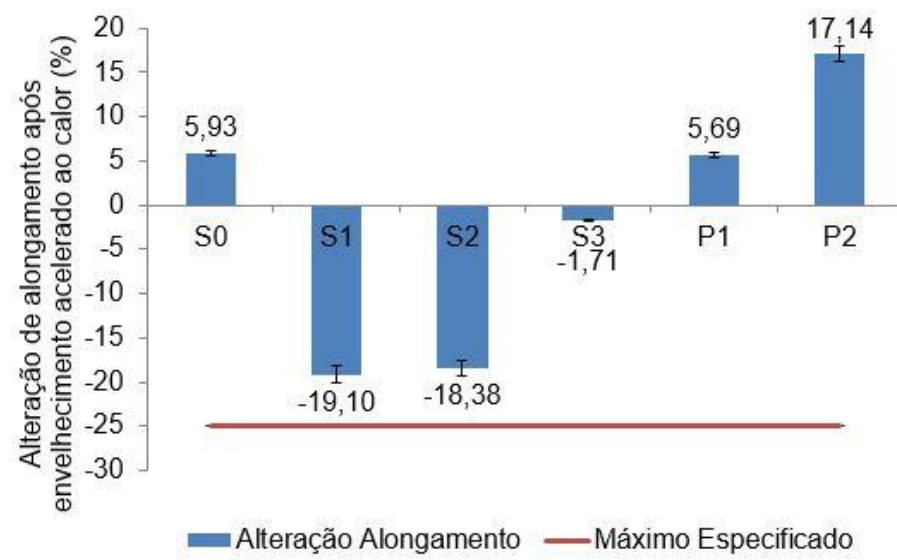

Figura 7: Resultados do ensaio de alongamento após envelhecimento acelerado em estufa (\%) do composto padrão e dos obtidos com as diferentes formulações propostas para o sistema de vulcanização.

Os resultados dos sistemas de vulcanização S1, S2 e S3 apresentaram valores coerentes com a especificação, ou seja, valores negativos. Para S1 e S2, não há variação significativa entre estes compostos, mas quando comparados com S3 há uma discrepância nos resultados, pois ao diminuir o teor de enxofre ocorrem melhores resultados em relação à resistência ao calor devido ao tipo de ligação formada ser mais estável termicamente $[3,4]$. Os sistemas de vulcanização S0, P1 e P2 apresentaram resultados positivos para este ensaio, não tendo valores condizentes com o especificado, pois somente são estabelecidos valores negativos.

\subsection{Densidade Absoluta}

Este ensaio não constava na especificação técnica do composto padrão, sendo realizado apenas para observar as modificações ocasionadas nos compostos testados devido às alterações nas formulações. A Figura 8 mostra os valores obtidos conforme as alterações realizadas nos sistemas de vulcanização.

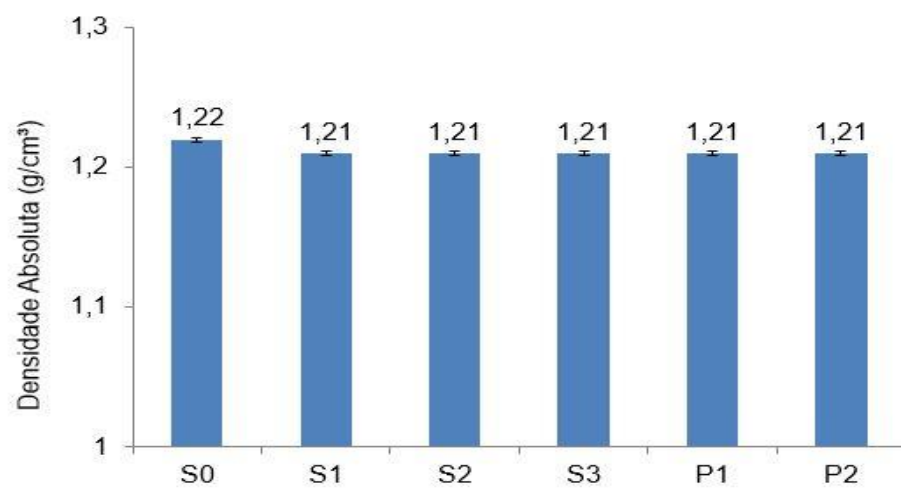

Figura 8: Resultados do ensaio de densidade absoluta do composto padrão e dos obtidos com as diferentes formulações propostas para o sistema de vulcanização.

Dos resultados apresentados na Figura 8, pode-se observar que não houve alterações significativas nos compostos testados, pois as alterações foram realizadas em matérias primas que não ocasionam modificações, devido às densidades destas serem muito próximas umas das outras, e por também serem 
utilizadas em quantidade relativamente baixas comparadas com as cargas de enchimento, cargas de reforço e plastificantes por exemplo.

\section{CONCLUSÕES}

As avaliações permitiram verificar os efeitos de diferentes sistemas de vulcanização, utilizando enxofre e peróxido orgânico, em compostos elastoméricos de SBR/NR. Pequenas alterações no sistema de vulcanização ocasionaram modificações consideráveis no composto. Com relação ao tempo de Scorch (ts2), os compostos contendo maior razão acelerador/enxofre apresentaram melhores resultados, ou seja, maior tempo de armazenamento antes do processamento, diminuindo o índice de refugo. A razão acelerador/enxofre influencia positivamente nos resultados das curvas reométricas para o teste de armazenamento entre o $1^{\circ} \mathrm{e}$ o $10^{\circ}$ dia útil, pois foram obtidas menores variações percentuais nestes tipos de sistemas de vulcanização. O sistema de vulcanização $\mathrm{S} 1$ que utiliza doador de enxofre e uma razão maior de acelerador/enxofre pode ser utilizado como formulação alternativa ao sistema de vulcanização padrão (S0), pois as propriedades avaliadas estão de acordo com as exigidas pela especificação técnica para este composto, apresentando maior tempo de armazenamento, minimizando a pré-vulcanização.

\section{AGRADECIMENTOS}

Os autores agradem à Indústria de Artefatos de Borracha Wolf Ltda., UNIVILLE, CAPES e CNPQ.

\section{BIBLIOGRAFIA}

[1] COELHO, D. B., MARIANO, R. M., ZINE, C. L., et al., "Misturas NR/SBR: influência da ordem de adição dos aditivos da mistura e do tipo de carga sobre propriedades mecânicas", Polímeros, São Carlos, v. 21, n. 3, pp. 204-209, 2011.

[2] PERES, A. C. C., LOPES, L. M. A., VISCONTE, L. L.Y., et al., "Uso de DSC na determinação de parâmetros de vulcanização de látex de borracha natural", Polímeros, São Carlos, v. 16, n. 1, pp. 6165, 2006.

[3] OLIVEIRA, M. A. S., CASSU, S. N., MELLO, S. A. C., et al., "Influência do método de vulcanização nas propriedades mecânicas e na densidade de ligações cruzadas da borracha natural", Polímeros, São Carlos, v. 26, pp. 43-48, 2016.

[4] MANSILLA, M. A., MARZOCCA, A. J., MACCHI, C., et al., "Natural rubber/styrene-butadiene rubber blends prepared by solution mixing: Influence of vulcanization temperature using a Semi-EV sulfur curing system on the microstructural properties", Polymer Testing, v. 63, pp. 150-157, 2017.

[5] GUERRA, B., FURTADO, C.R.G., COUTINHO, F. M. B. "Avaliação Reológica de Elastômeros e suas Composições”. Polímeros, São Carlos, v. 14, n. 4, pp. 289-294, 2004.

[6] ROCHA, E. C., LOVISON, V. M. H., PIEROZAN N. J. Tecnologia de Transformação dos Elastômeros, Centro Tecnológico de Polímeros SENAI - CETEPO, São Leopoldo (2003).

[7] WEBER, T., ZANCHET, A., CRESPO, J. S., "Caracterização de artefatos elastoméricos obtidos por revulcanização de resíduo industrial de SBR (copolímero de butadieno e estireno)", Polímeros, São Carlos, v. 21, n. 5, pp. 429-435, 2011.

[8] BENAZZOUK, A., DOUZANE, O., MEZREB, K., "Physico-mechanical properties of aerated cement composites containing shredded rubber waste". Cement \& Concrete Composites, v. 28, pp. 650-657, 2006.

[9] CHOU, L. H., LU, C. K., CHANG, J. R. "Use of waste rubber as concrete additive", Waste Management Research, v. 25, pp. 68-76, 2007.

[10] BENAZZOUK, A., DOUZANE, O., MEZREB, K. "Thermal conductivity of cement composites containing rubber waste particles: Experimental study and modelling", Construction and Building Materials, v. 22 , pp. 573-579, 2008. 
[11] NACIF, G. L., PANZERA, T. H., STRECKER, K. C., et al., "Investigations on cementitious composites based on rubber particle waste additions”, Materials Research., São Carlos, v. 16, n. 2, pp. 259-268, 2013.

[12] Silveira, P. M., ALBUQUerQUE, M. C. F., CASSOLA, S., et al., "Estudo do comportamento mecânico do concreto com borracha de pneu", Matéria(R.J.), v. 21, n. 2, pp. 416-428, 2016.

[13] NORHAZARIAH, S., AZURA, A. R., SILVAKUMAR, R., et al., "Effect of different preparation methods on crosslink density and mechanical properties of carrageenan filled natural rubber (NR) latex films", Procedia Chemistry, v. 19, pp.986-992, 2016.

[14] LUNA, C.B.B., SILVA, D.F., ARAÚJO, E.M. "Efeito dos agentes de compatibilização SBS e SEBSMA no desempenho de misturas de poliestireno/resíduo de borracha de SBR", Matéria(R.J.), v.21, n.3, p.632-646, 2016.

[15] SISANTH K. S., THOMAS M.G., ABRAHAM J., THOMAS S. "General introduction to rubber compounding", Progress in rubber nanocomposites, v. 1, pp. 1-39, 2017.

[16] MILANI, G., LEROY, E., MILLANI, F., et al., "Mechanistic modeling of reversion phenomenon in sulphur cured natural rubber vulcanization kinetics", Polymer Testing. v. 32, pp. 1052-1063, 2013.

[17] NABIL, H., ISMAIL, H., AZURA, A. R. "Optimisation of acceletrators and vulcanising systems on termal stability of natural rubber/recycled ethylene-propylene-diene-monomer blends", Materials \& Desing, v. 53, pp. 651-661, 2014.

[18] ASTM D 5289 (1995 reap. 2012) - Vulcanization Using Rotorless Cure Meters1.

[19] ASTM D 412 (2006) - Standard Test Methods for Vulcanized Rubber and Thermoplastic Elastomers Tension1

[20] ABNT NBR 7462 (1992) - Elastômero Vulcanizado - Determinação de Resistência à Tensão de Ruptura.

[21] ASTM D 573 (1999 reapr. 2015) - Test Method for Rubber. Deterioration in an Air Oven.

[22] ABNT NBR 7318 (2015) - Elastômero Vulcanizado Para Uso em Veículos Automotores - Determinação da Dureza.

[23] ASTM D 395 (2001), método B - Test Methods for Rubber Property. Compression set.

[24] ASTM D 297 (1993 reapr. 1998) - Test Methods for Rubber Property Chemicals A

nalysis - item 16.3 .

[25] GRISON, E. C., BECKER, E. J., SARTORI, A. F. Borrachas e seus aditivos, componentes, influências e segredos. 1 ed., Porto Alegre, Suliani, 2010.

[26] ARAVANIS, E.A. Efeito do sistema de reticulação nas propriedades de compostos para peças de engenharia do setor automotivo, Dissertação de M.Sc., Universidade Federal do Rio Grande do Sul, Porto Alegre, 2006. 